\title{
RECURSOS EDUCACIONAIS ABERTOS PARA MOBILIZAÇÃO DO CONHECIMENTO EM EDUCAÇÃO DE FORMA CRÍTICA
}

\author{
OPEN EDUCATIONAL RESOURCES FOR KNOWLEDGE MOBILIZATION IN \\ EDUCATION IN A CRITICAL AND EMANCIPATORY WAY
}

\section{RECURSOS EDUCATIVOS ABIERTOS PARA MOVILIZACIÓN DEL CONOCIMIENTO EN EDUCACIÓN DE FORMA CRÍTICA}

\author{
Juliana Sales Jacques ${ }^{1}$; Elena Maria Malmann²; Sabrina Bagetti ${ }^{3}$
}

\begin{abstract}
RESUMO
Os Recursos Educacionais Abertos (REA), por meio do compartilhamento aberto em rede, são mobilizadores do conhecimento em Educação com democratização de práticas e consideração da pluralidade de ideias e contextos educacionais. A problemática é investigar os desafios da mobilização do conhecimento educacional, em cursos de formação de professores, através da coautoria de REA. Objetiva-se, portanto, dialogar sobre a mobilização do conhecimento em práticas educacionais abertas por meio dos REA. Para tanto, em movimento espiral cíclico de pesquisa-ação, como ciência educacional crítica, sustentaram-se ações e operações para compreensão teórica, política e ideológica do movimento REA e o coautorar de criações abertas, em cursos de formação inicial de professores de uma Universidade Pública. As inferenciações, em cada etapa cíclica, subsidiam a análise dos REA produzidos como resultado de pesquisa-ação. Diante disso, conclui-se que os REA potencializam a produção de teoria na prática, uma vez que as relações dialógicas, potencializadas pela coautoria, produzem diferentes efeitos de sentido que aprimoram, reformulam e instituem novos conhecimentos em Educação, prontos para ação e intervenção.
\end{abstract}

PALAVRAS-CHAVE: Recursos Educacionais Abertos; Mobilização; Conhecimento; Formação de professores.

\footnotetext{
${ }^{1}$ Doutora em Educação - Universidade Federal de Santa Maria (UFSM) - Santa Maria, RS - Brasil. Professora Adjunta no Departamento de Administração Escolar (ADE) do Centro de Educação (CE) da Universidade Federal de Santa Maria (UFSM) - Santa Maria, RS - Brasil. E-mail:juletras.jacques@gmail.com

2 Pós-doutora pela Universidade Aberta de Portugal - Lisboa, PT. Doutora em Educação - Universidade Federal de Santa Catarina (UFSC) - Santa Catarina, SC - Brasil. Professora-pesquisadora do Departamento Administração Escolar (ADE). E-mail: elena.ufsm@gmail.com

${ }^{3}$ Doutoranda em Educação Universidade Federal de Santa Maria (UFSM) - Santa Maria, RS - Brasil.

Coordenadora Pedagógica do Ensino Fundamental I do Colégio Riachuelo de Santa Maria. Professora de Educação Básica - Santa Maria, RS - Brasil. E-mail: sabribagetti@gmail.com

Submetido em: 09/05/2018 - Aceito em: 03/08/2018
}

(C) ETD- Educação Temática Digital Campinas, SP $\quad$ v.21 n.4 $\quad$ p.1043-1059 out./dez. 2019 
ABSTRACT

Open Educational Resources (OER), through open sharing in a network, are mobilizers of knowledge in Education with democratization of practices and consideration of the plurality of educational ideas and contexts. The problem is to investigate the challenges of the mobilization of educational knowledge in teacher training courses through OER co-authorship. The aim is, therefore, to talk about the mobilization of knowledge in educational practices opened through the OER. To do so, in a cyclical spiral movement of action research as critical educational science, actions and operations were supported for the theoretical, political and ideological understanding of the OER movement and the co-authoring of open creations in initial teacher training courses of the University. Inferences at each cyclical stage subsidize the analysis of OER produced as a result of action research. In view of this, it can be concluded that OERs potentiate the production of theory in practice, since the dialogical relations fostered by co-authorship produce different meaning effects that improve, reformulate and institute new knowledge in Education ready for action and intervention.

KEYWORDS: Open Educational Resources; Mobilization; Knowledge; Teacher training.

\section{RESUMEN}

Los Recursos Educativos Abiertos (REA), a través del compartir abierto en red, son movilizadores del conocimiento en Educación con democratización de prácticas y consideración de la pluralidad de ideas y contextos educativos. La problemática es investigar los desafíos de la movilización del conocimiento educativo en cursos de formación de profesores a través de la coautoria de REA. Se pretende, por lo tanto, dialogar sobre la movilización del conocimiento en prácticas educativas abiertas por medio de los REA. Para ello, en movimiento espiral cíclico de investigación-acción, como ciencia educativa crítica, se sustentaron acciones y operaciones para la comprensión teórica, política e ideológica del movimiento REA y el coautor de creaciones abiertas, en cursos de formación inicial de profesores de una Universidad pública. Las inferencias en cada etapa cíclica subsidian el análisis de los REA producidos como resultado de investigación-acción. En este sentido, se concluye que los REA potencian la producción de teoría en la práctica, ya que las relaciones dialógicas potenciadas por la coautoria producen diferentes efectos de sentido que mejoran, reformulan e instituyen nuevos conocimientos en Educación listos para la acción e intervención.

PALABRAS CLAVE: Recursos Educacionales Abiertos; movilización; conocimiento; Formación de profesores.

\section{INTRODUÇÃO}

"[...] na foz do rio é que se ouvem os murmúrios de todas as fontes. " (João Guimarães Rosa, 1985)

O rio, ao desaguar em outro fluxo de água, traz consigo "os murmúrios de todas as fontes" (Guimarães Rosa, 1985) que o compõem e definem suas particularidades. Essas particularidades composicionais aglutinam-se formando um novo curso natural. Em analogia, a foz de um rio assemelha-se ao processo de mobilização do conhecimento em Educação, haja vista o seu potencial fundador, pois, no findar de um curso, um novo fluxo emerge. $E$ segue. Em processo contínuo, o rio desembocará suas águas, findar-se-á e originará novos cursos. Essa ação contínua de, ao mesmo tempo, findar-se e fundar-se é o que produz propulsão. Da mesma forma, o conhecimento em Educação é propulsionado quando se findam os prazos de pesquisa e se formulam proposições teóricas. Ou seja, o conhecimento 
mobilizado e mobilizador na Educação nunca se finda em si mesmo, mas funda, ciclicamente, novos saberes. Isto é, produz efeitos de sentido quando mobilizado para ação, intervenção, aplicação prática (Levesque, 2009) sustentada na interlocução.

Pelo seu potencial de abertura "técnica e legal" (Amiel, 2014), os Recursos Educacionais Abertos (REA) são potencializadores da mobilização do conhecimento em Educação. Isso, porque, não findam no compartilhamento para sua mera utilização, mas, em um movimento cíclico ascendente de coautoria, fundam novas produções teórico-práticas. Nesse sentido, envolvem planejamento, ação, observação, reflexão e replanejamento, tanto na produção original quanto na obra derivada. Em cada contexto educacional, ecoam diferentes prioridades na formação; em outras palavras, ecoam as vozes na interlocução do coautorar para sintonizar, aprimorar e produzir conhecimento que gere outros novos conhecimentos mobilizadores de ação e intervenção.

Nessa esteira epistemológica, a preocupação de promover a coautoria de REA, como estratégia mobilizadora de conhecimento, é latente. Desse modo, realizaram-se ciclos espiralados de pesquisa-ação em equipes compostas por docentes e estudantes em formação inicial de professores, numa universidade púbica no Estado do Rio Grande do Sul (RS), Brasil. O planejamento, a ação, a observação, a reflexão e o replanejamento centraram-se na produção de conhecimento teórico-prático sobre metodologia, didática e práticas do ensino da língua portuguesa para os anos iniciais do Ensino Fundamental de nove anos. Nesse sentido, à luz dos princípios de abertura, REA foram produzidos e compartilhados em rede visando à implementação, na prática, do conhecimento construído ao longo do processo formativo da docência.

Assim, nas páginas seguintes desta produção, compartilha-se, no capítulo 1, em movimento dialógico, os sentidos produzidos sobre REA discorrendo sobre seus princípios e suas potencialidades para a mobilização do conhecimento. No capítulo 2, apresenta-se, ao leitor, as etapas cíclicas de pesquisa-ação que sustentaram ações e operações assentadas em duas vertentes: estratégica e organizativa. No capítulo 3, a partir dos dados produzidos, analisa-se criticamente os desafios contemporâneos da mobilização do conhecimento educacional, em cursos de formação de professores nas universidades, através da coautoria de REA. Por fim, nas considerações finais, infere-se que os REA promovem a produção de teoria na prática, uma vez que as relações dialógicas potencializadas pela coautoria produzem diferentes efeitos de sentido que aprimoram, reformulam e instituem novos conhecimentos em Educação. 


\title{
2 COAUTORANDO REA PARA MOBILIZAÇÃO DO CONHECIMENTO EM EDUCAÇÃO
}

Os REA ou Open Educational Resources (OER) são dispositivos educacionais, científicos e tecnológicos que se constituem como estratégia de mobilização do conhecimento. Isso, porque, promovem a criação, a recriação e o compartilhamento aberto de conteúdos intencionalmente educativos, ampliando as possibilidades de realização da Educação em todos os níveis e modalidades, inclusive a não formal (Unesco, 2012).

O cenário que origina os REA é conhecido como o movimento educação aberta, que emerge tanto da tradição educativa de partilha de boas ideias entre professores e estudantes, quanto da cultura de integração das tecnologias educacionais em rede, com os princípios da colaboração através da coautoria. Esse movimento pauta-se na premissa de que professores e estudantes devem ter a liberdade de usar, personalizar, contextualizar, melhorar e redistribuir os recursos educacionais, sem restrições. Nesse sentido, possibilitando abertura para além do acesso, potencializa não somente difusão de conhecimento, mas viabilidade para sua aplicação em ações interventivas, nos diferentes contextos e setores educacionais emergentes ou consolidados.

Como marco histórico do movimento que fomenta a reutilização de REA, tem-se o Fórum sobre o impacto de Softwares Didáticos Abertos no Ensino Superior nos países em desenvolvimento, realizado em 2002, sob a gestão da Organização das Nações Unidas para a Educação, Ciência e Cultura (Unesco). Além disso, em 2012, o Congresso Mundial sobre REA gerou a chamada Declaração de Paris, documento que sistematiza uma das definições mais difundidas para abordar o atual conceito de REA:

\begin{abstract}
materiais de ensino, aprendizagem e investigação em quaisquer suportes, digitais ou outros, que se situem no domínio público ou que tenham sido divulgados sob licença aberta que permite acesso, uso, adaptação e redistribuição gratuitos por terceiros, mediante nenhuma restrição ou poucas restrições. O licenciamento aberto é construído no âmbito da estrutura existente dos direitos de propriedade intelectual, tais como se encontram definidos por convenções internacionais pertinentes, e respeita a autoria da obra (Unesco, 2012, p. 1).
\end{abstract}

Nesse viés, os REA podem constituir-se em diferentes gêneros: livros didáticos, livros científicos, artigos científicos, vídeos, softwares, imagens, áudios, dentre outros. Toda produção pode ser REA, desde que contemple os princípios basilares dos 5Rs estabelecidos por Wiley (2014) e definidos pelas seguintes liberdades:

1) Reter - o direito de fazer e guardar cópias próprias do conteúdo (por exemplo, download, duplicar, armazenar e gerenciar);

2) Reutilizar - o direito de usar o conteúdo de várias formas (por exemplo, em uma classe, em um grupo de estudo, em um site, em um vídeo);

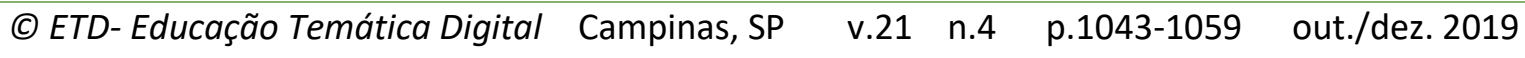


3) Rever - o direito de adaptar, ajustar, modificar ou alterar o conteúdo em si (por exemplo, traduzir o conteúdo para outro idioma);

4) Remixar - o direito de combinar o conteúdo original ou revisado com outro conteúdo aberto para criar algo novo (por exemplo, incorporar o conteúdo em criações personalizadas);

5) Redistribuir - o direito de compartilhar cópias do conteúdo original, suas revisões, ou seus remixes com os outros (por exemplo, dar uma cópia do conteúdo a um amigo).

Os REA, portanto, são materiais, técnicas ou tecnologias (softwares) que contribuem não só para o acesso ao conhecimento, mas também para o seu aprimoramento e novas construções na prática. Para tanto, faz-se necessário que estejam disponíveis "numa licença flexível ou em domínio público para que outras pessoas possam fazer uso ou modificações sem problema com direitos autorais" (Serra e Okada, 2014, p. 3).

Nesse viés, destaca-se que as produções protegidas por direito autoral podem ser licenciadas de maneira aberta. O licenciamento aberto acontece quando o detentor de direito autoral compartilha com a sociedade parte de seus direitos patrimoniais de autor, como os direitos de cópia, reprodução, redistribuição e até criação de obras derivadas, possibilitando a livre utilização para quem manifestar interesse.

As licenças Creative Commons, por exemplo, possibilitam a padronização de declarações de vontade no tocante ao licenciamento e a distribuição de conteúdos culturais ou hipermídias (textos, músicas, imagens, filmes e outros), de modo a facilitar seu compartilhamento e sua reutilização. Assim, permitem, ao detentor de direitos autorais, definir o que o público pode fazer com suas produções. As opções de licenciamento do Creative Commons (alguns direitos reservados) possibilitam desde a abdicação quase total dos direitos patrimoniais até opções mais restritivas que vedam a criação de obras derivadas ou uso comercial dos materiais licenciados.

Isso implica conhecimento teórico sobre os princípios que regem os REA. Ademais, pressupõe que os ciclos espiralados de reter, rever, remixar e redistribuir sejam mantidos no autorar e no coautorar, a fim de que a abertura do recurso produzido sempre seja mantida. Ao autorar, "[...] o sujeito está, de alguma forma, inscrito no texto que produz" (Orlandi, 2001, p. 76), marcando "sua individualidade na expressão de seu querer-dizer, de seu projeto discursivo, enfim, de sua potencialidade para o diálogo" (Francelino, p. 109, 2011). o diálogo é concebido no momento em que a criação possibilita encontro interacional entre autor, texto e leitor. Na expressão do "querer-dizer", o autor tem de fornecer subsídios para que o leitor produza sentidos a partir da criação. Para além do campo da linguagem, no movimento REA, essa potencialidade para o diálogo diz respeito à liberdade para o coautorar através da adaptação da obra produzida, visando à mobilização do conhecimento. 
ntendido nessa perspectiva, alinhar a produção e o compartilhamento de REA, num processo autônomo de pesquisa-ação em cursos universitários de formação de professores, é sempre produção da mudança, é mobilizar saberes de fluência tecnológico-pedagógica para sustentar performances interventivas, mobilizadoras e concretas na resolução de problemas da vida prática e cotidiana. Nesse sentido, "para que o sujeito se coloque como autor", no movimento REA, "ele tem de estabelecer uma relação com a exterioridade, ao mesmo tempo que se remete à sua própria interioridade: ele constrói assim sua identidade como autor. Isto é, ele aprende a assumir o papel de autor e aquilo que ele implica. (Orlandi 2001, pp. 78-79). Implica contemplar além da estética inerente à criação, a ética de produzir ou adaptar REA, permitindo tanto "abertura legal" quanto "abertura técnica" (Amiel, 2014, p. 198). Dessa forma, materiais abertos, tanto no formato quanto nas condições de reúso, podem potencializar autoria e coautoria de novos conhecimentos em rede.

Argumenta-se, portanto, que os REA geram mecanismos de superação da produção em série, através da multiplicação da interatividade com as tecnologias em rede e da interação colaborativa. Nesse contexto, a mobilização do conhecimento por meio dos REA pressupõe ações de produção, reúso, revisão, remixagem e redistribuição de materiais (princípios dos REA). A escolha de como o material será disponibilizado é que define as possibilidades de sua (re)utilização, revisão, readaptação nas práticas educacionais. As possibilidades de readaptação potencializam a flexibilidade da ação educacional em todos os sentidos. O compartilhamento dessas readaptações promove expansão e democratização de recursos educacionais, através da coautoria ampliando a relevância sociocultural do trabalho docente nas universidades.

A colaboração gera autoria e coautoria em rede; o compartilhamento das produções, dependendo do tipo de licenciamento, pode democratizar seu acesso e reutilização, mobilizando conhecimento em Educação. Nesse sentido, no campo da metodologia e da didática, materiais à luz dos princípios de REA contribuem para a superação da educação bancária (Freire, 2015) assentada na alienação de professores à mera reprodução e repetição de propostas pedagógicas prontas, e na sua passividade mediante às situações-limite da realidade concreta.

Assim, a produção de REA é compreendida como estratégia de mobilização do conhecimento. A mobilização centra-se tanto na aquisição (conhecimento adquirido), que privilegia o conteúdo e o significado do conhecimento, quanto no reúso na ação, na intervenção, que privilegia a sua organização e formalização (Caria, 2007). Mobilizar o conhecimento conjuga, simultaneamente, sua utilização e procura, permitindo desenvolver um conhecimento construído na interação social e adaptado à singularidade das pessoas que interagem, sendo capazes de guiar novas construções de aprendizagens (Caria, 2007). Em outras palavras, a relevância tecnológico-pedagógica e, por isso mesmo, sociocultural dos REA 
está na produção de conhecimento na prática, através de ação e intervenção sustentadas na interlocução de coautores em diferentes contextos educacionais.

\section{PESQUISA-AÇÃO: ETAPAS CÍCLICAS DA PRODUÇÃO DE REA COMO ESTRATÉGIA DE MOBILIZAÇÃO DE CONHECIMENTO}

Esta análise crítico-interpretativa sustenta-se nos planos qualitativos da pesquisa-ação educacional. Na concepção de Kemmis e Mctaggart (1988), a pesquisa-ação se caracteriza pela tomada de ações coletivas, formadas por grupos de participantes em situações sociais, com o objetivo de melhorar as práticas sociais e educativas, pois "proporciona um meio para trabalhar que vincula teoria e prática a um todo único: ideias em ação" (Kemmis e Mctaggart, 1988, p. 10).

Desse modo, é concebida como uma prática colaborativa e participativa, visto que o pesquisador não é o único ator do processo investigativo, mas, sim, coautor atuando colaborativamente com seus pares em torno de uma mesma preocupação temática. Investigar ativamente significa planejar, agir, observar e refletir cuidadosa e sistematicamente sobre uma realidade concreta (Kemmis e Mctaggart, 1988), a fim de potencializar mudanças na prática através da intervenção. Isso porque a pesquisa que não se usa não existe (Fischman, 2001).

Assim, o percurso investigativo ocorreu em meio a um processo assentado em duas vertentes: estratégica e organizativa. De forma simultânea, integram quatro etapas: planejamento, ação, observação e reflexão. Essas etapas implicaram, em cada momento, um olhar retrospectivo e prospectivo, gerando uma espiral autorreflexiva de conhecimento e ação. (Kemmis e Mctaggart, 1988).

A pesquisa-ação consistiu-se na coautoria de REA no Ensino Superior, especificamente no curso de licenciatura em Pedagogia, na disciplina de Língua Portuguesa e Educação, do Centro de Educação (CE) de uma Universidade Pública. Compreendeu o período do primeiro semestre de 2016, com a participação de 30 (trinta) estudantes, os quais, em colaboração, produziram 7 (sete) REA. Para que o fazer fosse coerente com o pensar certo do movimento REA, desde o planejamento dos recursos e das atividades de estudo até a coautoria propriamente dita, teve-se como fio condutor os seus princípios basilares para que a mobilização do conhecimento educacional de fato ocorresse. Assim, o quadro 1 expõe o movimento de mobilização realizado em cada etapa cíclica da pesquisa-ação.

Quadro 1- Etapas cíclicas da pesquisa-ação: aplicação prática e intervenção

\begin{tabular}{|l|llll|}
\hline $\begin{array}{c}\text { Etapas cíclicas da } \\
\text { pesquisa-ação }\end{array}$ & \multicolumn{3}{|c|}{ Atividades desenvolvidas } \\
\hline \multirow{2}{*}{ (Re)planejamento } & $\begin{array}{l}\text { Organização didático-metodológica das práticas educacionais de produção de } \\
\text { REA para mobilização do conhecimento educacional em rede, através de: a) } \\
\text { seleção de materiais didáticos em formato REA; b) elaboração de atividades de }\end{array}$ \\
\hline
\end{tabular}




\begin{tabular}{|c|l|}
\hline & $\begin{array}{l}\text { estudo para compreensão teórica, ideológica e política do movimento REA; c) } \\
\text { planejamento de atividades de pesquisa e identificação de REA em portais } \\
\text { públicos; d) planejamento de produção, em formato aberto, de práticas de } \\
\text { ensino da língua portuguesa para os anos iniciais do Ensino Fundamental. Ao } \\
\text { mesmo tempo em que o planejamento findou no ciclo da ação, fundou-se } \\
\text { novamente no replanejamento dessas ações a partir das situações-limite } \\
\text { vivenciadas e refletidas na prática interventiva. }\end{array}$ \\
\hline \multirow{5}{*}{ Ação } & $\begin{array}{l}\text { Desenvolvimento das práticas educacionais, planejadas no primeiro ciclo da } \\
\text { pesquisa-ação, para a produção de REA em prol da mobilização do } \\
\text { Conhecimento educacional. Findou-se e fundou-se novamente a partir do } \\
\text { replanejamento }\end{array}$ \\
\hline Regservação & $\begin{array}{l}\text { Registro do olhar e escuta atentos aos discursos dos estudantes nos diálogos } \\
\text { sobre REA e no monitoramento da coerência entre o fazer docente certo e o } \\
\text { pensar certo no movimento REA. Findou-se no momento em que se iniciou o } \\
\text { ciclo da reflexão sobre os registros, fundando-se novamente no } \\
\text { desenvolvimento das ações (re)planejadas. }\end{array}$ \\
\hline Reflexão & $\begin{array}{l}\text { Análise crítico-interpretativa os desafios da mobilização do conhecimento } \\
\text { educacional em cursos de formação de professores através da coautoria de } \\
\text { REA Findou-se quando iniciou o ciclo de (re)planejamento, visando à produção } \\
\text { de viáveis-possíveis às situações-limite. Findou-se, novamente, a partir das } \\
\text { ações replanejadas e das observações registradas. }\end{array}$ \\
\hline
\end{tabular}

Fonte: Autoras

A base teórica que sustentou o movimento cíclico da pesquisa em cada uma das etapas desenvolvidas e potencializou a construção de sentido (e seus efeitos) manteve-se centrada no dialogismo entre e nos ciclos espiralados. Quando se planeja, reflete-se a partir da observação do contexto investigado; quando se observa, reflete-se prospectando ações; quando se age, o faz de modo refletido - reflexão teórico-prática que perpassou a ação e que refletiu as concepções na realidade educacional.

Sob o viés dialógico-problematizador de matriz freireana, produziu-se REA em blogs para o compartilhamento das práticas educacionais de leitura e escrita, na dimensão interacional da linguagem, para os anos iniciais do Ensino Fundamental da Educação Básica. Em todas as etapas da pesquisa-ação, inferenciações foram produzidas na construção de sentidos a partir de observação, registro e reflexão sobre, na e para a prática interventiva. Tais inferenciações subsidiam a análise crítico-interpretativa do potencial dos REA como relevância sociocultural e científico-tecnológica para a mobilização do conhecimento em Educação.

\section{ANÁLISE CRÍTICO-INTERPRETATIVA DOS REA PARA MOBILIZAÇÃO DO CONHECIMENTO EM EDUCAÇÃO}

Na pesquisa-ação, produz-se, de modo colaborativo, conhecimento concreto aplicado na prática via intervenção. Nesse sentido, se um dos princípios basilares da pesquisa-ação é o trabalho colaborativo nas situações de intervenção, os REA acentuam essa potencialidade.

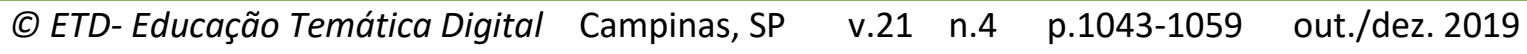


Isso, porque, através da coautoria, mobilizam o conhecimento educacional na contemporaneidade marcada pelas tecnologias em rede, pela convergência de mídias, pela otimização e rapidez na atualização de conteúdos curriculares e remodelização de materiais e métodos de ensino-aprendizagem.

Diante disso, o conhecimento que se tem produzido na prática, no curso de Pedagogia, gera impactos precisos na Educação Básica, uma vez que viabiliza, na formação inicial de professores, o compromisso de planejar e produzir práticas educacionais potencializadoras de ensino-aprendizagem em diferentes contextos educacionais. Como pressuposto da pesquisa-ação, vislumbrou-se transformação da/na prática de modo responsável e responsivo (Bakhtin, 2011; Sobral, 2014): responsável no sentido de sustentar-se na ética e na estética inerentes à coautoria de REA; responsivo no que se refere ao comprometimento de compartilhar produções prontas para aplicação na prática. Tanto o ato responsável quanto o ato responsivo da produção de REA sustentam a condução do conhecimento até o canal de chegada, que é a sua aplicação através da intervenção dialógica.

Nesse movimento responsável e responsivo, dos 7 (sete) REA produzidos, selecionouse um recorte para análise crítico-interpretativa. Assim, analisam-se 2 (dois) REA considerando o seu potencial de mobilização do conhecimento em Educação, pontuando os elementos éticos e estéticos que dão forma e conteúdo às criações. Os registros de observação subsidiam e sustentam a análise crítico-interpretativa apresentada a seguir, a partir dos recortes dos blogs em formato REA intitulados: Blog de Língua Portuguesa e Educação (Figura 1) e Práticas em Língua Portuguesa e Educação (Figura 2).

\section{Blog de Língua Portuguesa e Educação}

segunda-feira, 4 de julho de 2016

\section{Referências}

BRANDÃO, S. V. Laboratório de redação: para séries iniciais do ensino fundamental. São Paulo: Paulinas, 2003.

NASPOLINI, A. T. Tijolo por Tijolo: prática de ensino de língua portuguesa. São Paulo: Editora FTD, 2010.

Postado por Blog de Língua Portuguesa e Educação às 21:13 Nenhum comentário:

$M[t \mid$ P $G+1$ Recomende isto no Google
E Blog de Língua Portuguesa e Educação

Somos acadêmicas do $5^{\circ}$ semestre do Curso de Pedagogia, da Universidade Federal de Santa Maria. A realização deste blog contempla uma atividade pertencente à disciplina de Língua Portuguesa e Educação, sob orientação da Professora Juliana Sales Jacques. Visualizar meu perfil completo

(Continuação) 
Produção de anúncio publicitário para comercialização de um produto

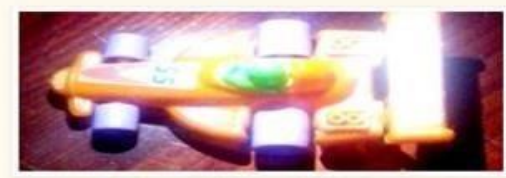

Autoras: $\mathrm{XXX}$

RECORD, o mais novo carrinho do mercado:

O carrinho de corrida que faltava na sua coleção!

Ele é inquebrável, suas cores săo vibrantes, ele brilha no escuro: Alcança maior velocidade em poucos segundos.

Edição limitada para colecionadores.

Trabalhando o texto no sentido sociointeracionista.

Primeira etapa:

a) Recorte o título do conto.

b) Formule três opções diferentes de títulos para o conto que vocè escolheu.

- A amizade pesa mais

- É melhor brincar do que brigar

- Quanto vale os seus amigos?

c) Formule três questões de pré-leitura (que tratem do tema de um modo geral e que auxiliem o leitor na descoberta do título do conto).

- Voce tem um melhor amigo e alguma vez já brigou com ele?

- 0 que pesa mais para vocé, os defeitos ou as qualidades de seus amigos?

- Você sabe valorizar os seus amigos?

- 0 que seu amigo faz de bom para você?

Segunda etapa:

d) Exponha as três opções de títulos e acrescente a essas opções o título original.

e) Troque o seu conto com o conto de outro grupo.
Atividade de leitura interrompida; atividade de sequenciar partes do texto; atividade de preencher lacunas e atividade relacionando texto e ilustração

Leitura interrompida



Autoras: XXX

Atividades realizadas sobre a temática "Trabalhando o texto no sentido interacionista da leitura" (elaboração de títulos diferentes para o conto; mudança do final do conto; questões de pré-leitura; produção textual com diferentes sentidos (valor semântico) das palavras)

Atribuição - Não Comercial - Compartilha Igual CC $\mathrm{BY}-\mathrm{NC}-\mathrm{NC}$

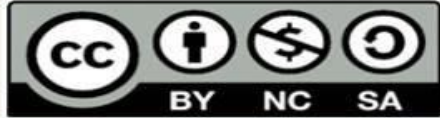

Este trabalho está licenciado com uma Licença Creative Commons Atribuição-NãoComercial-Compartilhalgual 4.0 Internacional..

Figura 1 - Blog em formato REA: Língua Portuguesa e Educação

Fonte: Recortes do Blog produzido como REA. Acesso: http://linguaportuguesaeeduc.blogspot.com.br/



(Continuação)

(C) ETD- Educação Temática Digital Campinas, SP $\quad$ v.21 n.4 p.1043-1059 out./dez. 2019 


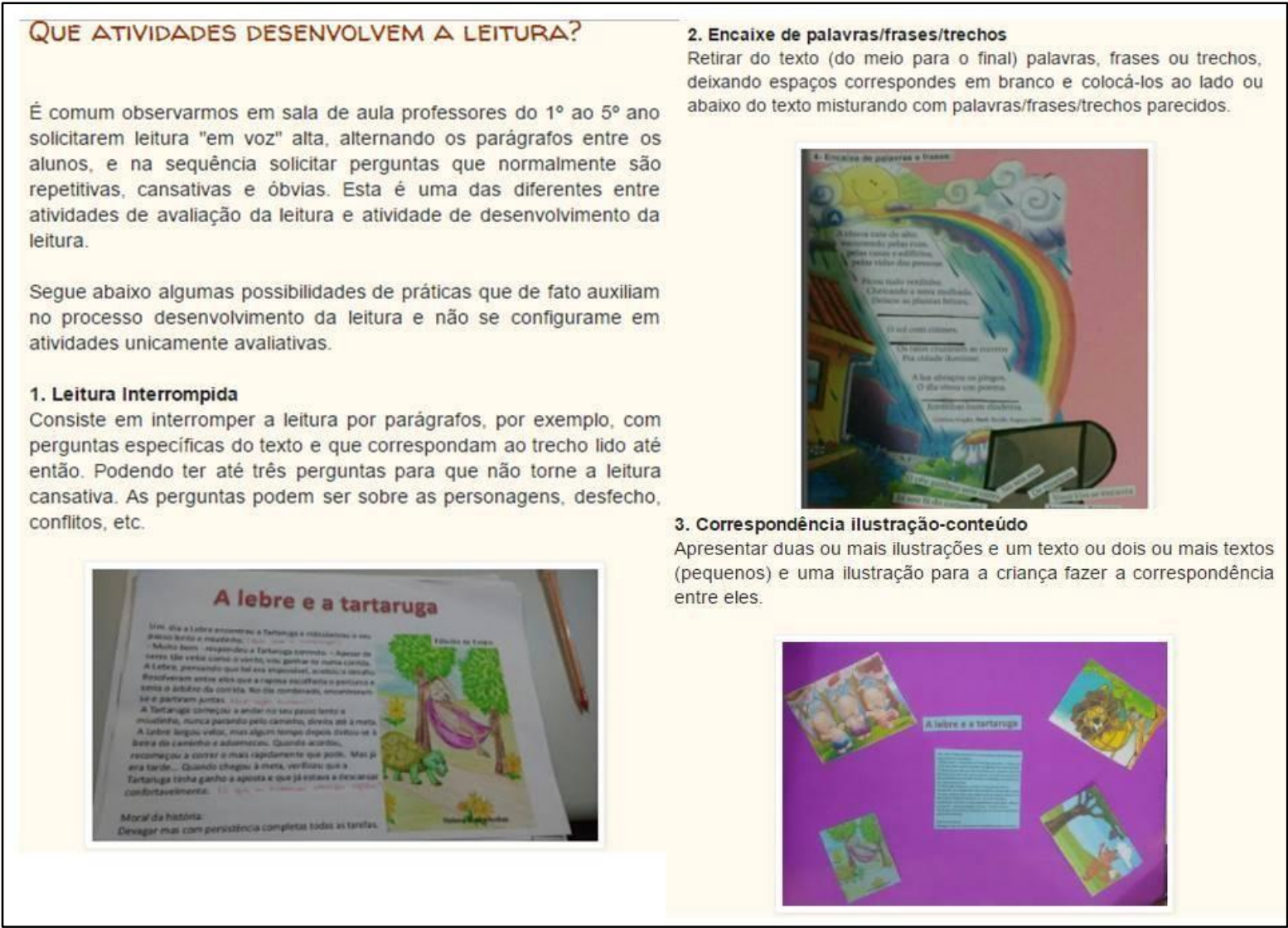

Figura 2 - Blog em formato REA: Práticas em Língua Portuguesa e Educação Fonte: Recortes do Blog produzido como REA. Acesso: http://linguaportuguesaeeducacao11.blogspot.com.br/

Nos recortes dos dois blogs em formato REA (Figuras 1 e 2), percebe-se responsabilidade e responsividade com/ao movimento REA no que se refere à escolha da licença, haja vista que ambas permitem adaptações na obra, por isso os blogs constituem-se de fato REA. Nesse sentido, potencializam a mobilização do conhecimento em Educação compartilhando, de modo aberto, práticas educacionais de ensino da língua portuguesa para os anos iniciais do Ensino Fundamental, embasadas teoricamente. Tais práticas, ao serem desenvolvidas ao longo da disciplina de Língua Portuguesa e Educação, sustentaram-se na concepção de linguagem como um lugar de interação social (Koch, 2010), cujas relações dialógicas produzidas no interior de cada enunciado e entre interlocutores visam à promoção de diferentes efeitos de sentidos que reflitam em determinada realidade educacional e a transforme. 
Ao produzir práticas educacionais sob a concepção teórica e epistemológica da transformação e da relevância sociocultural, o fazer estabeleceu coerência com o pensar certo. Isso, porque, não se limitou meramente ao saber fazer, mas centrou-se no objetivo e na finalidade desse fazer, considerando: o que fazer; para que fazer; para quem fazer; como fazer; o que se espera e o que se produz desse fazer. Houve um cuidado para que o processo fosse coerentemente conduzido, orientado até o ponto de chegada que é, de fato, o ensinoaprendizagem na Educação Básica. Produzir práticas educacionais abertas por meio de REA, na formação inicial de professores, gera implicações e impactos diretos na escola. Estabelecese, assim, relações dialógicas entre universidade e escola, mobilizando conhecimentos que possam ser aplicados na prática, refletidos, aprimorados e compartilhados com outros contextos educacionais.

Esta é a potencialidade mobilizadora dos REA: fazer com que o conhecimento produzido chegue ao seu local de destino organizado para ser aplicado e, mesmo assim, viável para continuidade de construção de novos saberes. Para tanto, as bases que sustentam o processo de produção têm de subsidiá-lo de modo que a aplicação do conhecimento produzido gere transformação na/da prática e, na interlocução entre os mediadores, novos conhecimentos sejam construídos. Pressupõe-se, nesse sentido, subsídios tanto para compreensão teórico-científica do objeto de estudo, quanto para compreensão política, ideológica, conceitual do movimento REA. A mobilização do conhecimento em Educação, no viés que se defende, constitui-se, portanto, das relações dialógicas entre o conhecimento sobre o objeto de estudo e de sua transposição no ensino-aprendizagem e o conhecimento sobre o movimento REA e suas implicações na prática do professor. Tudo isso em movimento cíclico de produção/aplicação-reflexão-produção/aplicação.

Defende-se que os blogs em formato REA produzidos mobilizam o conhecimento em Educação na interface entre as diferentes áreas, haja vista que são licenciados legalmente de modo aberto; compartilham práticas educacionais fundamentadas em uma concepção epistemológica e visão política, evidenciando a relação intrínseca entre teoria e prática. Entretanto, em alguns aspectos, as criações que, nas palavras de Bakhtin (2011), constituemse em objetos estéticos, denotam os desafios inerentes à mobilização do conhecimento por meio dos REA. Isso, porque, para que o fazer seja coerente com o pensar certo do movimento, tudo que perpassa tanto o processo quanto a criação tem de seguir os princípios de REA. Significa dizer que, se a finalidade é produzir REA, os elementos que o compõe tem de ter licença aberta.

Algumas imagens que compõem os objetos estéticos possuem licença fechada, como as que ilustram as práticas de estratégias de leitura: a imagem da fábula "A lebre e a tartaruga" e demais recortes que evidenciam as estratégias de leitura interrompida (Figuras 1 e 2), encaixe de palavras/frases/trechos (Figura 2), correspondência ilustração/conteúdo (Figura 2) foram extraídas de livros didáticos com licença fechada. $O$ fato de reutilizar 
materiais com licenças fechadas na produção do REA não impossibilita a mobilização do conhecimento, porém fragiliza a ética e a estética que dão forma e conteúdo à criação. Este é um desafio da coautoria de práticas educacionais em formato REA: produzi-las integrando somente REA.

A licença Creative Commons escolhida no blog Práticas em Língua Portuguesa e Educação (Figura 2) é a mais permissiva das seis licenças, todavia a criação como um todo não denota integralmente um dizer ético, ou seja, responsável com os princípios dos REA. Argumenta-se, diante disso, sobre a latente necessidade de produção e compartilhamento de REA para contemplar todas as demandas de coautoria coerentes com o pensar certo do movimento. O desafio da mobilização por meio dos REA é superar a "consciência ingênua" (Freire, 2015) através do esclarecimento sobre o conceito, a política e a ideologia dos REA e tudo que o perpassa. Ações estratégicas precisam ser planejadas e desenvolvidas para que de fato se avance para a "consciência crítica" (Freire, 2015) produzindo REA coerentes com o pensar certo.

Em contrapartida ao todo arquitetônico do blog evidenciado na figura 2, no blog Língua Portuguesa e Educação (Figura 1), a imagem/foto ilustrativa no anúncio publicitário para comercialização de um produto foi registrada pelos próprios estudantes, uma vez que não encontraram imagens abertas semelhantes ao produto anunciado. Isso denota compromisso ético e estético tanto com o processo de produção quanto com o resultado. Nesse sentido, ao analisar as condutas dos estudantes nas duas criações, percebe-se compreensões ou comprometimentos diferentes que implicam no modo como o conhecimento é mobilizado, ou seja, em que tipo de conhecimento se produz e se compartilha.

Todavia, somente o compromisso ético e estético com o movimento REA não basta para que a mobilização do conhecimento em Educação aconteça. Como se argumentou anteriormente, a mobilização ocorre nas relações dialógicas entre o ético e o estético no movimento REA e com o ético e o estético na apropriação e na transposição do objeto de estudo. Ao compartilhar práticas educacionais abertas, além de contemplar os princípios de abertura o conhecimento elucidado tem de estar pronto para utilização, reflexão, reformulação e reutilização. A escolha dos recursos léxicos e discursivos para compor a escrita, a fim de expor, descrever, argumentar sobre o objeto de estudo interfere no modo como esse conhecimento chegará ao interlocutor, implicando, muitas vezes, dificuldades na compreensão e na sua aplicabilidade prática.

Pode-se observar que o blog da figura 1 apresenta, ao interlocutor, as liberdades de REA. Todavia, não apresenta a descrição das atividades propostas para o ensino da língua portuguesa nos anos iniciais do Ensino Fundamental. Apenas apresenta a atividade realizada: questões de inferenciação e produção de anúncio publicitário. Nesse sentido, não apresenta 
um dizer ético que reflita compromisso com a interpretação do interlocutor, ou seja, com as implicações desse compartilhamento na prática.

Já o blog da figura 2, por mais que o todo arquitetônico da criação não denote um dizer ético, tendo em vista que abarca textos multimodais com licença fechada, há autoria no enunciado verbal expositivo das práticas educacionais desenvolvidas. Há exposição conceitual de cada estratégia de leitura e como podem ser desenvolvidas para a formação da habilidade leitora, bem como traz um breve resgate histórico das concepções de leitura para situar o interlocutor. Nesse sentido, não apresenta apenas o resultado (a prática realizada), mas também o processo de produção. Assim, há preocupação em estabelecer um encontro interacional entre autor, texto/REA e leitor/coautor. Portanto, potencializa a mobilização do conhecimento em Educação, uma vez que viabiliza condições éticas e estéticas para sua aplicação prática através da intervenção do professor (coautor) na Educação Básica. Estreita, diante disso, a relação dialógica entre universidade e escola.

\section{CONSIDERAÇÕES FINAIS}

No viés argumentativo balizador desta produção, defende-se a essencialidade da autoria e coautoria de REA, nos processos formativos de professores, a fim de mobilizar o conhecimento em Educação tanto nas universidades quanto nas escolas básicas. Nessa perspectiva epistemológica, entende-se ciência, tecnologia e sociedade numa dinâmica complexa em redes, o que implica parametrizar a pesquisa e a produção de conhecimento educacional por bases teórico-metodológicas crítico-interpretativas. 0 impulso transformador e emancipatório do movimento retrospectivo (avaliação) e prospectivo (deliberação) da pesquisa-ação gera produção da mudança educacional. Tal qual o movimento REA, sustenta-se em princípios basilares requerendo um estar e ser concretos, e não superficiais, cujo fazer certo precisa ser "rigorosamente coerente com o pensar certo" (Freire, 2015). O trabalho colaborativo nas situações de intervenção, além de promover construção de conhecimento sobre o coautorar no movimento REA, contempla, em sua essência, os princípios dos REA. Tudo isso para que a ética e a estética (Bakhtin, 2011; Sobral, 2014) perpassem o processo de produção aberta para mobilização de conhecimento no Ensino Superior, gerando impactos precisos na Educação Básica.

Nesse sentido, o movimento cíclico da pesquisa-ação potencializou a coautoria de REA no Ensino Superior, mobilizando conhecimento em Educação na interface entre a formação universitária e a prática educacional na Educação Básica. A análise crítico-interpretativa dos resultados obtidos no processo de criação (coautoria de REA) permite compreender seus princípios basilares e materializá-los. Dar forma ao conteúdo curricular é uma ação concreta de mobilização do conhecimento e, na linha argumentativa aqui marcada, situa-se na concepção de abertura desse movimento. Defende-se que os REA contribuem para a mudança, em larga escala, dos contextos educacionais marcados pela reutilização de 
materiais com licenças fechadas e, culturalmente, habituados à restrição do conhecimento à sala de aula.

Na medida em que foram produzidos e compartilhados os blogs no formato REA, evidenciou-se a mobilização do conhecimento científico-tecnológico, no prisma críticoemancipatório, implicando, concomitantemente, desenvolvimento e aprimoramento da compreensão teórica, política e ideológica, tanto no coautorar das criações abertas, quanto nos efetivos impactos no ensino-aprendizagem. O trabalho colaborativo, nas diversas situações de intervenção evidenciadas, além de promover a construção de conhecimento sobre o coautorar no movimento REA, contemplou, em sua essência, os princípios dos REA. Acentuou o potencial das ações e das intervenções colaborativas nas diversas situações de ensino-aprendizagem, flexibilizando a prática educacional no contexto contemporâneo, pela convergência de diferentes mídias inseridas nos blogs, pela otimização e rapidez na atualização de conteúdos curriculares disponibilizados.

O compartilhamento das produções com as licenças Creative Commons possibilitou a democratização de seu acesso e reutilização, potencializando a produção de teoria na prática. Isso, porque, as relações dialógicas constituintes e constitutivas da coautoria podem produzir diferentes efeitos de sentido que aprimorem, formulem novos conhecimentos em Educação, prontos para ação e intervenção nos diversos contextos educacionais escolares. Conclusivamente, o desenvolvimento da prática educacional de produção de REA em formato blog, no curso de Pedagogia, gerou impactos precisos, viabilizando, na formação inicial de professores, o compromisso de planejar e produzir práticas educacionais potencializadoras de ensino-aprendizagem em diferentes contextos educacionais, configurando-se como uma estratégia de mobilização do conhecimento em Educação'. 


\section{REFERÊNCIAS}

AMIEL, Tel. Recursos Educacionais Abertos: uma análise a partir do livro didático de história.

Revista História Hoje, v. 3, n. 5, p. 189-205, 2014.

BAKHTIN, Mikhail Mikhălovich. Estética da criação verbal. Livraria Martins Fontes, 1992.

BRAIT, Beth. Bakhtin: conceitos-chave. São Paulo: Contexto, 2005.

CARIA, Telmo H. Itinerário de aprendizagens sobre a construção teórica do objeto saber. Etnográfica. Revista do Centro em Rede de Investigação em Antropologia, v. 11, n. 1, p. 215-250, 2007.

FISCHMAN, Gustavo E.; SALES, Sandra Regina. Formação de professores e pedagogias críticas. É possível ir além das narrativas redentoras. Revista Brasileira de Educação, v. 15, n. 43, p. 3-18, 2010.

FISCHMAN, Gustavo E. Reflections about images, visual culture, and educational research. Educational Researcher, v. 30, n. 8, p. 28-33, 2001.

FRANCELINO, Pedro Farias. Enunciação, dialogismo e autoria em enunciados midiáticos verbo-visuais. MOARA-Revista Eletrônica do Programa de Pós-Graduação em Letras, v. 1, n. 36, p. 104-114, 2013.

FREIRE, Paulo. Ação Cultural: para a liberdade e outros escritos. São Paulo, SP: Paz e Terra, 2014.

FREIRE, Paulo. Educação como prática da liberdade. São Paulo, SP: Paz e Terra,, 2014.

FREIRE, Paulo. A importância do ato de ler. São Paulo, SP: Moderna. 2003

FREIRE, Paulo. Pedagogia do oprimido. 6.ed. Rio de Janeiro, RJ : Paz e Terra, 2015.

KEMMIS, Stephen; MCTAGGART, Robin. Cómo planificar la investigación: acción. Barcelona: Laertes, 1992.

KOCH, Ingedore Grunfeld Villaça. A inter-ação pela linguagem. São Paulo, SP: Contexto, 1992.

LEVESQUE, Peter. Knowledge mobilization works. Ottawa, Canada. Consultado el, v. 13, 2009.

ORLANDI, Eni Puccinelli. Análise de discurso: princípios e procedimentos. Campinas, SP: Pontes, 2001.

(C) ETD- Educação Temática Digital Campinas, SP $\quad$ v.21 n.4 p.1043-1059 out./dez. 2019 
ORLANDI, Eni Puccinelli. Discurso e leitura. São Paulo: Cortez, 2001.

ROSA, João Guimarães. Ave, palavra. Rio de Janeiro: Nova Fronteira, 1985.

SERRA, Antonio Roberto Coelho; OKADA, Alexandra. Mobilidade aberta: coaprendizagem e coinvestigação em ambientes acadêmicos. 2014. Disponível em:

http://oro.open.ac.uk/41788/ Acesso em: 12 fev. 2018

SOBRAL, Adail. Ético e estético: na vida, na arte e na pesquisa em Ciências Humanas. In:

Bakhtin: conceitos-chave. São Paulo, SP: Contexto, p. 103-121, 2014.

UNESCO. Declaração REA de Paris em 2012. Congresso mundial sobre Recursos

Educacionais Abertos (REA) de 2012. Disponível em: http://www.rea.net.br/site/declaracaorea-de-paris-2012/. Acesso em: 12 fev. 2018.

WILEY, David. The Access Compromise and the 5th R. Iterating toward openness, 2014.

Disponível em: http://opencontent.org/blog/archives/3221. Acesso em: 08 de set. 2018.

\section{Revisão gramatical realizada por:}

Juliana Sales Jacques

E-mail: juletras.jacques@gmail.com

\footnotetext{
i Pesquisa realizada com o financiamento do Conselho Nacional de Desenvolvimento Científico e Tecnológico (CNPq) e da Comissão de Aperfeiçoamento de Pessoal do Nível Superior (CAPES), e viabilizada com o auxílio financeiro do Edital Pesquisador Gaúcho da Fundação de Amparo à Pesquisa do Estado do RS (FAPERG), frente as ações do Grupo de Estudos e Pesquisas em Tecnologias Educacionais em Rede (GEPETER), do Centro de Educação da Universidade Federal de Santa Maria (UFSM).
} 